\section{Lathyrogenic Activity in vitro}

Reasons have already been given for the view that the basic aortic lesion in experimental lathyrism is mainly a failure of formation of elastic tissue ${ }^{1}$. An attempt has since been made to investigate, in vitro, the effect of various lathyrogenic substances on the production of elastic fibres.

Explants were taken from the ventricles of chick embryo heart (the great vessels being carefully removed so that the only elastic tissue in the initial explants was the small amount present in the coronary vessels) and were cultured by a modification of the method described by Bloom ${ }^{2}$ using Waymouth's medium $^{3}$ with 10 per cent calf serum for 10-12 days at $39^{\circ} \mathrm{C}$. as the fluid phase. Whether the explants were grown in fibrin clot or directly on glass, in stoppered glass tubes or in Petri dishes in an atmosphere with 5 per cent carbon dioxide did not affect the results. Some additional results obtained from experiments with mouse embryo hearts do not differ markedly from those with chick embryo hearts and are not reported in detail here.

A preliminary experiment showed that fibres similar to those described by Bloom ${ }^{2}$ first appeared after 7 days incubation, and were well formed after 10 days. Subsequent cultures were therefore examined after this time. The fibres stain with Weigert's method for elastica, with orcein, and with Gomori's aldehyde fuchsin, providing strong presumptive evidence that they are indeed elastica; further investiga. tions are being made into this matter. The fibres usually run parallel to each other to form a cirele or arc of a circle around the explant at the junction of the original tissue and the monolayer extending from it. They appear to have formed immediately under the surface layer of cells at the farthest point from the glass. In a fow cases, particularly in small explants, the fibres form a disorganized network, or may show some radial orientation. In the presence of lathyrogenic substances these fibres were not found.

For assay of lathyrogenic activity each experiment comprised multiple cultures and graded concentrations of test substances. Only those experiments in which one or more control cultures produced elastica were considered. In successful cultures 40 out of 51 (78 per cent) of the controls produced elastica. When $\beta$-aminopropionitrile hydrochlorideknown to be lathyrogenic in vivo-was added to the cultures it was found that a concentration of $2 \mathrm{mgm}$./ $\mathrm{ml}$. killed the majority of the explants, and in the few cases where the cells survived elastic fibres were never formed. With lower concentrations down to $80 \mu \mathrm{gm} . / \mathrm{ml}$., although the explants were healthy as frequently as in the control cultures, elastic fibres were never formed. With still lower concentrations the percentages of healthy cultures producing elastic fibres were as follows: $16 \mu \mathrm{gm} . / \mathrm{ml}$., 10 per cent; $3.2 \mu \mathrm{gm} . / \mathrm{ml}$., 12.5 per cent; $0.64 \mu \mathrm{gm} . / \mathrm{ml}$., 66 per cent. Two other compounds active in vivo, $\beta$-mercaptoethylamine $\theta^{4}$ and semicarbazide ${ }^{5}$, inhibited the formation of elastic fibres at concentrations of $3.4 \mu \mathrm{gm} . / \mathrm{ml}$. and $0.66 \mu \mathrm{gm} . / \mathrm{ml}$. respectively. Sodium propionate and $n$-propylamine, both inactive in vivo, were also inactive in vitro at concentrations of up to $364 \mu \mathrm{gm} . / \mathrm{ml}$. and 0.16 per cent respectively; higher concentrations caused cell death. Assuming uniform distribution of lathyrogenic substances throughout animal tissue, the doses of $\beta$-aminopropionitrile hydrochloride, $\beta$-mercaptoethylamine and semicarbazide which inhibit the formation of elastica in vitro correspond to the concentrations calculated as being present in the tissues of mice treated with these compounds and showing rupture of the corta. The results demonstrate that lathyrogenic substances act at a cellular level, and the parallelism between the in vivo and in vitro findings supports the original hypothesis that the aortic rupture in experimental lathyrism is secondary to a failure of formation of normal elastic tissue.

\section{H. Morag MoCallum}

Department of Pathology,

\section{John PaUL}

Department of Biochemistry, The University, Glasgow.

${ }^{1}$ McCallum, H. Morag, Nature, 182, 1169 (1958).

${ }^{2}$ Bloom, W., Arch. Exp. Zellforsch., 8, 6 (1929).

${ }^{3}$ Waymouth, Charity, J. Nat. Cancer Inst., 22, 1003 (1959).

4Dasler, W., and Milliser, R. B., Proc. Soc. Exp. Biol. Med., 98, 759 (1958)

' Dasler, W., Proc. Soc. Exp. Biol. Med., 97, 112 (1958).

\section{An Early Test for Possible Skin Carcinogens}

Is previous papers ${ }^{1-4}$ it has been shown that it is possible by a tetrazolium reduction method to estimate changes in the rate of formazan deposition in the epidermis of hairless mice after different skin irritants.

A characteristic reaction was observed after the application of some carcinogenic substances and after local irradiation with X-rays. The topical application of carcinogens produced a short initial rise in formazan deposition, followed by a depression of longer duration. An initial decrease in formazan deposition was observed after the application of some non. carcinogenic compounds. It was suggested that an initial rise in formazan deposition might be specific for skin irritants with carcinogenic potency.

Examining the validity of this hypothesis, $a$ blindtest with 20 different compounds was performed. The substances were dissolved in benzene and the different samples were indicated by $A, B, C, \ldots$ etc.

Hairless mice, 8 males and 8 females for each test substance, were given $0.005 \mathrm{ml}$. of the solution as a single, topical application to a circumscribed area of the skin. The formazan deposition per mgm. dry epidermis per hour measured on the first and the second day after the application was recorded. It was postulated that mean relative values of $1 \cdot 100$ and above should indicate a compound with skin carcinogenic potency.

The results of the blind test are given in Table 1 . The values are arranged in order from the lowest to the highest. To the right is presented the list of answers, including an indication of the carcinogenic potency of the substances. In this communication only those substances are listed as complete carcinogens which each alone are known to produce epidermoid carcinomas in mouse skin after topical application.

It appears that there is a correlation between such complete carcinogenic activity and initial rise in formazan deposition. The above-mentioned hypothesis is thus given some further support and the method may probably be used as an early test for possible skin carcinogens. It must, how. ever, be kept in mind that correlation never proves specificity. 